\title{
Curanderos, peregrinos y turistas. Procesos interculturales en la sociedad cusqueña contemporánea*
}

\author{
Guillermo Salas Carreño**
}

En las cumbres del Ausangate, hundiendo sus puñales en un horizonte de añiles, se levanta la más poderosa wak'a del Tahuantinsuyo, su nombre qheswa es poético, los indios le llaman Qoyllorit'i (lucero de nieve o nieve de luceros), su culto milenario está grabado con párrafos de sangre en la historia.

Alfonsina Barrionuevo (Cuzco Mágico)

\section{SOBRE LA PEREGRINACIÓN DE QOYLLUR RIT'I}

Lo andino a propósito de cómo se ve la peregrinación

La imagen que se ha ido construyendo sobre la peregrinación de Qoyllur Rit'i es la de una fiesta indígena en la que los campesinos de los altos terrenos andinos - generalmente pastores de puna - acuden anualmente a un lugar inhóspito, al pie de un nevado, para reafirmar su relación con la naturaleza y agrade-

* La primera versión de este texto fue la monografia «La tradición religiosa andina: entre el esoterismo y la reinvención», presentada en 1998 para el curso "Teoría Antropológica 2», dictado por la profesora Norma Fuller en el pregrado de Antropología de la Pontificia Universidad Católica del Perú. Posteriormente, en 1999, una versión corregida de ese mismo trabajo ganó una mención honrosa en el concurso de ensayos «El Perú al fin del milenio», organizado por la Red para el Desarrollo de las Ciencias Sociales en el Perú. Agradezco los comentarios que los profesores Norma Fuller y Alejandro Diez hicieran de la primera versión de este texto, así como los que Alexander Huerta, Marcel Velásquez, Esteban Arias y Juan Javier Rivera hicieran a partir de la versión de 1999. Asimismo, agradezco a quienes participaron conmigo, en distintos años, en la peregrinación de Qoyllur Rit' $i$ : los colegas Adriana Dávila y Juan Javier Rivera, y Juan Salas, estudiante de Artes en la misma casa de estudios. Se decidió no variar fundamentalmente la versión presentada al concurso de la RED (1999); por esta razón, no se han añadido nuevos datos de campo.

** Licenciado en Antropología. Pontificia Universidad Católica del Penú. Doctorando en Antropología Cultural. Universidad de Michigan. 
cer y propiciar la fertilidad de la tierra y de los animales. Los campesinos van a adorar a los apus' y a las huacas, ${ }^{2}$ que no han podido ser vencidos no obstante los quinientos años de presencia de la Iglesia y de los occidentales. En medio de esto se recrearian mitos de origen y las relaciones entre grupos étnicos cuyos orígenes se pierden en las épocas incaicas y preincaicas. Estos origenes se expresan a través de danzas como los qollas ${ }^{3}$ o los chunchos, de las naciones (Quispicanchis, Paucartambo, etc.), o en la ascensión de los $u k u k u s^{4}$ a un nevado.

De acuerdo con esta interpretación de la peregrinación, este ritual estaría alterado por los cambios que se han ido produciendo en las últimas décadas. La incursión de los juegos con piedras y las alasitas, la presencia del mercado, los peregrinos urbanos mestizos, la disminución de comparsas de wayri chun$\operatorname{chos}^{5}$ y la aparición de las bulliciosas bandas de metales amenazarian la esencia y el sentido primordial de la peregrinación.

Para otros, las posiciones esencialistas son trasnochadas y arcaicas. Lo que se encuentra en Qoyllur Rit' $i$ son quechuas empobrecidos que van renunciando a sus raíces y se van volviendo occidentales. Ya no mantienen esa relación armoniosa con la naturaleza; de alguna manera su ser indígena se ha visto alterado y trastocado por la influencia de Occidente, del mercado, de los medios de comunicación. Qoyllur Rit'i sería una sobrevivencia -más o menos bastar$\mathrm{da}$ - de lo que alguna vez fue una gran fiesta inca relacionada con las pléyades. El futuro de lo indígena en la peregrinación está signado por la pérdida inevitable.

Las posiciones antes presentadas no han sido construidas por la gran mayoría de los peregrinos que anualmente inundan la rinconada de Sinak'ara a 4800 m.s.n.m. sino por intelectuales, investigadores, periodistas y artistas más bien urbanos y de clase media, cusqueños, peruanos y extranjeros. Ambas po-

Espíritus de las montañas.

2 Lugares sagrados.

3 Los danzantes de qolla representan a comerciantes llameros procedentes del altiplano puneño.

4 Los $u k u k u s$ son personajes que representan a un ser mítico mezcla de oso y de ser humano. También están asociados a las alpacas. En cada comparsa (grupo de danzantes) hay por lo menos dos ukukus.

5 Los bailarines de wayri chuncho están recargados con lo que sería lo mas esencialmente andino en Qoyllur Rit'i. Las comunidades tradicionales y cercanas al santuario -que se cuentan entre las más pobres - son las que traen esta danza con sus tocados y pelucas de plumas de guacamayo y lanzas de chonta. La danza representa a los indígenas selváticos. Estos danzarines son los preferidos del Señor y la música de esta danza es utilizada por todas las demás cuando se trasladan de un lugar a otro. 
siciones son dos extremos de un mismo eje. Comparten el presupuesto de que las culturas son esenciales, que tienen un núcleo duro y definido que no cambia con el tiempo. Además, las culturas luchan entre ellas, como organismos coherentes, y tienen cierto grupo selecto (que podrían ser los sacerdotes de $Q^{\prime}$ ero $^{6}$ en este caso) encargado de mantenerlas intactas mediante mecanismos misteriosos. También está presente el supuesto de que un individuo o un grupo maneja solamente una identidad y que, al empezar a manejar otra, inevitablemente la primera va siendo dejada de lado y desaparecerá con el tiempo.

Si se entiende la cultura como un conjunto de sistemas simbólicos (Geertz 1973) lo anterior es fácilmente rebatible. La cultura es la forma en que los seres humanos aprehendemos el mundo. Cada momento es una situación nueva que es asimilada a través de nuestra experiencia previa. Nuestro universo simbólico se está reconstituyendo cada vez que nos enfrentamos a hechos nuevos. La transformación de una cultura es uno de sus modos de reproducción. «En la acción o en el mundo - técnicamente, en los actos de referencia- las categorías culturales adquieren nuevos valores funcionales. Cargados con el mundo, los significados culturales son por lo tanto alterados. Se deduce que si las relaciones entre las categorias cambian, la estructura se transforma» (Sahlins 1988: 130-131).

Visto desde este punto de vista, es lógico que, ante posibilidades de apropiación de nuevos universos simbólicos, cualquier individuo y, por ende, cualquier cultura que entre en contacto con otra se apropiará de todo lo que de ella le resulte útil (Fuenzalida 1993: 11, Golte 1981). Es preciso entender que una cultura se reinventa constantemente en las interacciones entre los seres humanos que forman parte de una sociedad. Una cultura no es un ente supraindividual que tenga una existencia independientemente de las personas y de sus interacciones.

Estos sistemas simbólicos se pueden entender también como un conjunto de soluciones acumuladas a problemas surgidos en la historia de una sociedad. Estos problemas nacen en la relación con la naturaleza y con otros hombres. En la medida en que los problemas cambien, las soluciones también lo harán. Es obvio que, desde que se dio el contacto entre las culturas occidentales y las andinas, los problemas han ido variando mucho a través del tiempo. La vigencia de soluciones a problemas está relacionada a su capacidad de actualización. Lo valioso y útil se conserva, y lo otro se deja de lado, adoptando soluciones nuevas sin importar si provienen de «culturas enemigas»

6 La comunidad de Q'ero, llamada el último ayllu inca, es el paradigma de la pervivencia de lo inca en las comunidades cusqueñas contemporáneas. (Cf. Flores y Fries 1989). 
(Golte op. cit.: 59). Asi, no tiene sustento suponer costumbres y principios inmutables en una cultura.

Una aproximación más adecuada hacia una cultura en particular (como la cultura andina) es entenderla como un proceso en el tiempo. La particularidad de cada cultura no se debe a una esencia inmutable sino a un proceso. Cuando miembros de culturas diferentes se encuentran -es decir, empiezan a interactuar- no lo hacen en relaciones de igualdad. Inevitablemente se establecen entre ellos jerarquias en diferentes ejes que pueden tender hacia la horizontalidad o la verticalidad.

El proceso de interacción entre diferentes culturas, la interculturalidad, que empieza con estos encuentros, va reconfigurando y transformando a los grupos involucrados, en la medida en que sus miembros y los universos simbólicos de estos se encuentran frente a situaciones radicalmente nuevas y enfrentados a universos simbólicos ajenos. Se van estableciendo y consolidando relaciones jerárquicas entre sus miembros $\mathrm{y}$, a su vez, las propias culturas van tomando características nuevas que las hacen diferentes a las culturas que originalmente se encontraron. El proceso es complejo y multivoco. En la medida en que mayor sea la jerarquía entre miembros de las diferentes culturas, y se vaya configurando un nuevo sistema político, este último tendrá mayores características de la cultura hegemónica. En un nivel formal, la cultura hegemónica busca no adoptar formalmente elementos culturales de la subordinada o los adopta en la medida que le son útiles (por ejemplo, las estrategias de gobierno indirecto a través de estructuras políticas indigenas de base). Mediante herramientas políticas, la ideología, la religión, los ritos, la educación y la historia, entre otros discursos, fabrica justificaciones de la situación jerárquica y va construyendo discursos que subvaloran a los subordinados.

Hay que tener en cuenta también que una cultura no es un todo uniforme. Dentro de ellas hay muchos grupos diferentes, determinados por distintos ejes de ordenamiento social: el económico, el étnico, el de género, el de prestigio, etc. Los grupos distintos - y los individuos dentro de ellos- reaccionarán de diferentes maneras frente al proceso intercultural y tendrán estrategias políticas diferentes. Las estrategias de defensa de los intereses de grupo no siempre van a la par de la defensa de los intereses de los demás grupos de la misma cultura. Las culturas resultantes de un proceso intercultural largo (a estas alturas, culturas complejas que incluyen muchas subculturas) no pueden trazar una línea clara y directa, y pretender ser las versiones actuales de una u otra de las culturas originales. 
En los Andes se ha tenido un largo y muy complejo proceso intercultural que empieza -para los fines de este texto- con la llegada de los españoles.? Lo andino presentaba una complejidad y diversidad muy grandes. Si bien las culturas andinas compartían, de alguna manera, una misma matriz cultural (hecho que podría estar en debate), estamos hablando de estructuras políticas, idiomas, religiones, estrategias económicas, estructuras sociales y recursos diferentes. Por otro lado, lo occidental en este proceso también es muy complejo. Quizá se pueda apreciar esto más claramente en el tiempo. Primero llegaron militares españoles; luego, burócratas; más tarde, se configuró el grupo de criollos en contraposición a los españoles (ambos grupos seguirían siendo occidentales); después, grupos diferentes de criollos (terratenientes y oligarcas). Paralelamente, llegaron inmigrantes africanos, chinos y anglosajones. Además hubo diferentes influencias externas que se recibieron de acuerdo con los contextos mayores en los que la colonia o la república se encontraban involucradas.

Así, lo que se tiene actualmente en los Andes es resultado de un largo proceso que no puede ser analizado con criterios maniqueos de occidental y andino claramente delimitados y aplicados a largos periodos temporales (Ansión 1994). Lo quechua andino contemporáneo, en el imaginario de la gran mayoría de peruanos, está asociado directamente con el poncho y el chullo, ${ }^{8}$ con masticar coca, con las llamas, con lo campesino comunero y la extrema pobreza. También lo quechua está asociado a lo indio, a lo cholo, es decir, a uno de los escalones más bajos de la estratificación social que los peruanos manejamos. Lo quechua, en el imaginario de la sociedad urbana, es un conjunto de atributos culturales socialmente estigmatizados.

Los estudios sobre economía campesina muestran las múltiples restricciones que impiden pensar en la agricultura en los Andes como la actividad más viable para el desarrollo económico de la población rural del país. Desde la calidad del suelo, la escasez de agua, la incertidumbre del clima y la baja productividad hasta las politicas de importación y macroeconomía del país hacen que los campesinos tengan que mantenerse «en las fronteras del mercado» para poder reproducirse (González de Olarte 1994).

La asociación entre lo quechua y lo campesino comunero es directa. En la medida en que los campesinos comuneros luchan por acceder a otros espacios que les posibiliten otras actividades económicas van dejando de ser campesi-

$7 \quad$ Es decir, el inicio del proceso intercultural podría colocarse en otra época dependiendo de los intereses del estudio y de las posibilidades de información disponible. Por ejemplo, el proceso intercultural Inca-Chimú o Chavín-Paracas.

El chullo es una prenda de vestir para la cabeza, de lana y tejida a mano. 
nos y, al mismo tiempo, van perdiendo sus atributos quechuas externos (el poncho, el chullo, el quechua, etc.). Un quechuahablante monolingüe se encuentra en una situación de desventaja muy grande frente a un hispanohablante en su relación con la sociedad oficial, con el aparato legal y con el ejercicio de otras actividades económicas adicionales a la agricultura.

Los campesinos andinos ven que las posibilidades de sus hijos no serán las mismas si no hacen todo lo posible por apropiarse de las herramientas de los poderosos, y el primer paso será el castellano. La lucha por la escuela ha sido una de las más tenaces y generalizadas acciones de las comunidades y poblaciones campesinas. El padre campesino desea que su hijo hable castellano; su sueño es que logre ser un ingeniero. En este sentido, lo quechua empobrecido, estigmatizado, relacionado simbólicamente con lo campesino comunero, tiende a autodisolverse, al menos en la forma estereotipada en que se lo concibe cotidianamente.

Todo esto debe tomarse en cuenta cuando se habla de la identidad andina y cuando se lamenta la pérdida de las costumbres que configuran la imagen de lo quechua en el imaginario de la población urbana. Hay que decir también que no existe, y no ha existido, una identidad andina o india que pueda ser calificada como identidad étnica. Los pobladores del espacio rural andino no se identifican como indios ni como andinos. Lo hacen si es que les conviene identificarse como tales, si en un discurso dado «el término entraña mayor peruanidad», o en alguna coyuntura similar. Según señala Ortiz Rescaniere: "Con más frecuencia prefieren afirmarse peruanos, "humildes peruanos", "los auténticos", "los netos", pero tambiẻn les gusta decir ahora que son "mestizos", que ya no son como los incas, que están mezclados con españoles, o que son simplemente "gente que quiere progresar") (Ortiz Rescaniere 1998: 2).

Los pobladores andinos han estado siempre interactuando con formas culturales distintas, muchas variedades dialectales, diferentes especializaciones étnicas, diferentes idiomas. El andino muestra una fascinación por lo extraño, una tendencia a la apropiación de lo nuevo. ${ }^{9}$ En este sentido, ser o no ser no es tan dramático para los pobladores rurales o para los peruanos populares de origen andino. Se es diferente en cada contexto y, en cada uno de ellos, se tienen lealtades diferentes, se vive un presente denso y un yo frágil en el tiempo. Estas características hacen que las personas de origen andino sean gente abier-

$9 \quad$ Esta característica -en su versión más sofisticada - fue la que permitió el éxito del Estado inca y, a la vez, fue su mayor logro: la capacidad de una rápida asimilación de los logros tecnológicos de los otros culturales y una tolerancia politicamente condicionada a otras formas culturales (organización social, religión, idioma), todo entrelazado en un complejo sistema de reciprocidad. 
ta al cambio, dispuesta a transformarse, a apropiarse de símbolos ajenos, a ser cosmopolitas (ib.). «Así, un adulto se sentirá y afirmará, según la ocasión, como un "neto", un "indio descendiente de los incas", un hijo de Chipiupata, o mestizo, de tal provincia, limeño, peruano, norteamericano. $Y$ todos esos rótulos los asumirá con sinceridad y cariño; pero claro, el pueblo natal como la familia nuclear son los primeros y más entrañables espacios identificadores» (ib.: 7).

Las identidades se crean, se construyen, son ejercicios de memoria selectiva (Hall 1995). Sin embargo, normalmente se tiene una imagen de qué es lo andino (de cómo era y cómo debería seguir siendo para no dejar de serlo) que lo muestra estereotipado y estático. Se tiene una gran admiración por lo inca y se valora lo quechua actual como sobrevivencia de lo incaico. Así, las comunidades campesinas serian herederas de los ayllus incas, y el Chiaraje,$^{10}$ una demostración de que los Q'eros, hoy en dia, adoran al sol y no a Cristo. Todo este conjunto de visiones de lo andino tiene una historia y se ha ido tejiendo en una interacción constante entre el sentido común y los estudios académicos. El indigenismo cusqueño y la Antropología andinista, desde lo académico, han tenido un papel importante en este proceso (Cf. Remy 1990; Poole 1991).

\section{Los protagonistas: endógenos y exógenos}

Conforme la sociedad rural ha ido cambiando, la peregrinación de Qoyllur Rit'i también lo ha ido haciendo. Ahora hay un gran componente de peregrinos provenientes de la ciudad del Cusco y, en mucha menor proporción, de Urcos y Sicuani. La mayoria de los citadinos llega individualmente, aunque también hay comparsas. La población rural va al santuario colectivamente en comunidades, llevando una comparsa. A los dos grupos anteriores les llamo los endógenos a la fiesta, pues van principalmente a participar de esta como fieles y son los que hacen que esta sea posible. Su participación en la peregrinación esta íntimamente ligada a su socialización, enmarcada o fuertemente influida por la cultura campesina de la región. Su principal motivo es la fe en el Señor de Qoyllur Rit'i. Mientras las personas de la ciudad suben al santuario y pasan en él solo una noche (después de haber escuchado la misa, bajan al día siguiente), los campesinos permanecen durante casi todo el ciclo ritual, que dura más o menos una semana. Es obvio que dentro de esta categoria de endógenos se encuentra gente muy diversa, de diferente condición económica y

10 Es el nombre con el que se conocen las batallas rituales que se llevan a cabo el día de San Sebastián en las pampas de Chiaraje, Canas, Cusco. 
ocupacional cultural. El otro grupo, al que llamaré peregrinos exógenos, está constituido por turistas extranjeros, periodistas, fotógrafos y antropólogos. Los denomino así porque están allí principalmente como espectadores; van porque les atrae este fenómeno religioso. Su participación en la peregrinación —que puede tener profundas motivaciones religiosas - no es consecuencia directa de su socialización en la cultura regional.

El lugar de la peregrinación se encuentra a 4800 m.s.n.m. Los peregrinos campesinos suelen llegar en camiones soportando el polvo y el frío. Los de la ciudad tienden a llegar en omnibuses hasta Mahuayani. Desde ese punto se sube a pie los ocho kilómetros que restan. En el santuario no hay habitaciones donde hospedarse, salvo algunas comunidades que han construido sus celdas. La gran mayoría de la gente duerme - cuando lo hace - a la intemperie, arropada con una o dos frazadas y un plástico azul que se encuentra a la venta por un sol el metro. El suelo es un bofedal bastante húmedo. Durante el día tiene una consistencia algo fofa, pero en las noches es duro pues el agua que contiene está congelada. Las carpas y los plásticos amanecen con una delgada capa blanca de escarcha dura.

El contraste con los exógenos es bastante grande. Se dispone, en estos casos, de una carpa de alta montaña, ropa térmica, zapatos de trekking, aislantes de aluminio, bolsas de dormir, cámaras fotográficas o, en su defecto, cámaras de video. Hay que decir también que la cantidad de endógenos es inmensamente mayor a la de exógenos. Indagando luego por la percepción que tienen los endógenos de los turistas y en general de los exógenos (considerando que el entrevistador era uno de ellos), me sorprendió el grado de apertura que se tiene hacia los extraños: «¿Cómo se va a prohibir a alguien que venga a ver al Señor? El que viene a la peregrinación se hace automáticamente hermano, no importan su procedencia ni su color». Otras respuestas argumentaban que si él fuera como turista a España le gustaría ir a ver las danzas que tienen allá y ¿por qué le tendrían que prohibir si está gastando su dinero?

Las cámaras, por otro lado, en algunos casos son impertinentes y hasta violentas, y provocan reacciones hostiles. Pero también pueden provocar una interacción no conflictiva. Los ukukus se ponen más traviesos, actúan para la cámara. Lo mismo pasa con algunos danzarines, que aceptan posar para fotografias. Existe el sentimiento de que estos documentos rendirán provecho económico al extranjero, beneficio del que están excluidos y que se logra mediante sus imágenes y su fe. Asi, los que son filmados o fotografiados no tendrán reparo en pedir algo de dinero a cambio. 
¿Por qué van los endógenos?

No obstante las diferencias entre los peregrinos campesinos y los peregrinos urbanos, se puede decir que el motivo principal de ambos es la fe en que el Señor de Qoyllur Rit'i les cumpla un milagro, que puede ser algún tipo de beneficio material, satisfacción de necesidades urgentes, adquisición de bienes o de una nueva posición social. En el santuario hay un lugar donde se juega a tener lo que uno quiere que el Señor le conceda milagrosamente: Pucllanapata ('la explanada del juego').

Repartidos por el suelo, cientos (quién sabe si miles) de personas amontonan piedras, armando casas o estancias, corrales o canchones para llamas y alpacas, ferreterías o depósitos de cerveza, garajes para flotas inmensas de camiones o centros de estética. Las piedritas se convierten en paredes, techos, escaleras, camiones, ganado. Después de la construcción, para quien guste, vienen las transacciones y el regateo. "Vendo casa de tres pisos con agua, luz y chanchos», figuraba escrito en un trocito de papel de cuaderno escolar. Las conversaciones previas al pacto son serias, minuciosas, fieles al modo de ser real. "O sea, es tu sueño que quieres hacerlo realidad, y no lo vas a hacer en broma. Allá se hace en serio. Allá tú no tienes que jugar tampoco con ellos». (Dávila 1996: 2)

A continuación se pone un ejemplo de cómo se da una transacción en este ambiente lúdico de la peregrinación de Qoyllur Rit'i. Este muestra el grado de detalle con que se hacen las transacciones:

Tampoco tú vas a decir «estamos en mayo o junio». Dices: «No, estamos en diciembre». Entonces, el que va a comprar sabe en qué mes está. En mes de la escasez tú no vas a comprar a un precio alto, tienes el riesgo de que se mueran. Diciembre es la época de lluvia en que el pasto está verde y todos comen y se engordan bien. Tú haces las preguntas también. El comerciante que va a comprar tiene que convencerse. «Está bien para ti a 10 soles?», «No, papá, es mucho. Yo podría pagar 8 soles por cabeza, además estamos en diciembre y ahora se alimentan harto». «Y las crías que van a parir?». Bueno, llegan a 8 soles, uno dice: "Si hasta antes que me lo llevo, paren, es para ti. Pero si en el camino paren, yo me lo cojo, así se mueran». Ya arreglan. Dicen cuántas cabezas machos hay, cuántas cabezas hembras hay, todo. «iMira pues, son un montón, mira!». Y el otro le dice: «No sé, hay algunas que están pequeñitas, que son maltonitas [que todavía no se pueden preñar]». Empiezan a hablar: «No», «Que sí». Y sabes que están jugando, que el corral es un pedazo de tierra. Lo marcan con piedritas el canchón, y acá hay unas piedritas blancas, en orden, ésas son las llamas. Y por ahi dicen: «¿Tienes alpacas?», «Sí». Y hay otro canchón donde las 
piedritas son más oscuras. Es el juego. Pero ellos lo hacen tan real que juegan a eso. Uno puede decir: «Entonces, ¿cómo es, pues? ¿Hay tinka o no hay tinka?». "iHay! Sí, papá, disculpa». Saca una botella con agua, y unas copitas te sirven. Tinkar es compromiso de que se está quedando en un buen acuerdo. Como te digo, hemos hecho esa transacción, hemos celebrado el contrato, hemos hecho un documento, y han firmado. En todo caso, ellos no han podido firmar, han puesto sus huellas. Se lo ha arreado su ganado, se lo ha llevado. Y los dos estaban felices. Uno que queria negociar. Entiendo yo que ha querido tener en ese momento bastantes cabezas de llama para poder vender $y$ ha hecho el sueño. $Y$ el otro seguro estaba con deseos de comprar ganado, y ha «comprado». Y los dos se han quedado muy felices. Nosotros hicimos legalizar, para que no haya dolo [Entrevista realizada por Adriana Dávila, en 1996, a Fernando Pancorvo, peregrino de viaje urbano].

Las cosas que se piden son, por lo general, bienes materiales: casas, terrenos, ganado, negocios, camiones, carros, títulos universitarios, etc. También se pide por la salud, por un buen matrimonio, por la familia. De las 77 cartas al Señor de Qoyllur Rit'i publicadas por Flores (1997: 172-231) se tiene el siguiente registro de peticiones:

\begin{tabular}{|lc|}
\hline \multicolumn{1}{|c}{ Peticiones } & Cantidad \\
\hline & \\
Por la graduación / Educación estudios / Exámenes de ingreso a la universidad & 32 \\
\hline Por la familia: padre, madre, hermanos, abuelos, tíos, primos & 29 \\
\hline Por salud & 28 \\
\hline Trabajo / Para no perderlo / Por que no falte para el pan & 21 \\
\hline Protección del mal, de la envidia, de los enemigos & 19 \\
\hline Para conseguir dinero, pagar deudas, hacer negocio, pedir capital & 18 \\
\hline Pedir perdón por lo pecados, por errores, por no ir & 15 \\
\hline Por los amigos, compañeros & 11 \\
\hline Por el amor, conseguir buena pareja, felicidad & 10 \\
\hline Pidiendo tener casa & 7 \\
\hline Pidiendo tener vehiculo para trabajar & 6 \\
\hline Bendición & 5 \\
\hline Pidiendo castigo para los que les hacen mal & 2 \\
\hline Por sus enemigos, para que cambien & 2 \\
\hline Por los difuntos & 1 \\
\hline Para que no prospere un amor visto como peligroso & 1 \\
\hline Para viajar al extranjero & 1 \\
\hline
\end{tabular}

Fuente: Flores (1997: 77) 
Si bien estos datos podrían estar muy sesgados hacia la población urbana, muestran claramente que los pedidos al Señor están muy ligados a las necesidades y deseos materiales - concretos- que son capitales para las vidas de los que los piden. Para ilustrar las peticiones de los peregrinos campesinos usaré la etnografia de Gow y Condori. Los testimonios fueron recogidos alrededor de 1975, en la comunidad de Pinchimuro, que se encuentra a $10 \mathrm{~km}$ del pueblo de Ocongate. Al señor de Qoyllur Rit'i se le pide que las alpacas estén sanas y se reproduzcan, y que la chacra dé buenos frutos. Las mujeres piden destreza en los trabajos femeninos de hilar y tejer. Los mestizos piden dinero introduciendo sus cartas en la gruta de la virgen (Gow y Condori 1982: 89). Los que bailan de ukukus bailan imitan a las alpacas porque quieren tener alpacas. Suben a traer la nieve para curarse de las enfermedades. Los que bailan qolla quieren ser comerciantes. Los que bailan kachampa lo hacen «para tener ropa nueva, $[\ldots]$ para que no se envejezca rápido, $[\ldots]$ para tener harto producto» (ib.: 90-92).

Respecto al culto a los apus y su relación con el culto al Señor de Qoyllur Rit ${ }^{\prime} i$, la etnografia de Gow y Condori sostiene que se da un cierto paralelismo de cultos: «Si van, respetan a las dos cosas. Algunos si, otros no. No prenden velas. Ofrecen despachos nomás, no prenden velas. Durante la fiesta los que quieren se adelantan y hacen una ofrenda a los apus. Se van hasta el nevado. Delante de éste hay una punta. Allí hay una laguna para que se bañen ellos, para que ofrezcan un despacho. Algunos pero no todos. Los paqos, los que saben se van después a pedir perdón al señor y prender sus velas» (ib.: 95).

La impresión que tengo - después de cuatro años seguidos de acudir a la peregrinación - es que ambos cultos se dan dentro de una concepción coherente del mundo. La versión que resumiría la lógica de la relación entre ambos es la siguiente: se va donde el Señor de Qoyllur Rit'i para pedirle muchas cosas, entre ellas que el apu Sinakara o el apu Qolquepunku reciba sus despachos." Los despachos, o pagos al apu, se hacen en el nevado; y los pedidos al Señor, en el templo. La gran mayoría de peregrinos endógenos no habla de los apus. Parece ser que el culto en este santuario está claramente concebido como un culto al Señor de Qoyllur Rit'i. Esta concepción no quita que los atributos del Señor de Qoyllur Rit'i sean casi los mismos que los del apu Ausangate (el

1I Hay que aclarar que el santuario de Qoyllur Rit'i no se encuentra al pie del nevado Ausangate. Se encuentra al pie del nevado Qolquepuncu que es parte del grupo de nevados que reciben en general la denominación de Ausangate. Respecto al apu de este lugar hay diferentes versiones: unos dicen que es el apu Sinakara; otros, el apu Qolquepuncu; y hay quienes también hablan del apu Qoyllur Rit'i. 
apu más importante de la región) y que haya innegables elementos de religión indigena en los ritos (los ukukus, su ascensión al nevado, su bajada con bloques de hielo; danzar en honor a la divinidad; lo recargadas que están simbólica y étnicamente las danzas: el que la gruta de la Virgen y el soporte de la imagen del Señor sean rocas, ${ }^{12}$ etc.). Pero en el discurso de los endógenos no está presente una asociación directa entre la peregrinación y el culto a los apus.

Este hecho puede deberse, en parte, a que todo discurso oficial en el santuario hace referencia al Señor, entendido como Cristo. Los grupos de mayor poder (la hermandad y los sacerdotes) manejan el discurso católico cristiano y creo que, a estas alturas, este es un sentimiento generalizado. ${ }^{13}$

En general, los peregrinos endógenos dicen que la fiesta está mejorando. Dicen esto porque cada vez hay más comparsas, más gente. En general la fiesta está creciendo. Ahora hay aproximadamente cincuenta comparsas. En los años sesentas «si habían 15 era mucho». El hecho de que hayan más bandas de metales - cosa que aumenta la sonoridad en detrimento de la «belleza de los tradicionales pitos, violines o acordeones) (Poole 1988) - es para los campesinos tradicionales otro indicio de la mejora de la fiesta.

Los motivos de los exógenos: “¿Por qué has venido a sufrir con nosotros?»"

La razones de los exógenos son más diversas y no se concentran en pedir milagros al Señor. Los motivos que están presentes son, en algunos casos, ganas de conocer una fiesta andina, sin dar mayor explicación sobre el asunto. Antropólogos y otros científicos sociales - la mayoria estudiantes-, peruanos y extranjeros, están allí porque aprovechan que se encuentran en Cusco haciendo alguna investigación y quieren conocer más de la cultura andina. Hay una que estudia peregrinaciones en el centro del país, por lo que esta peregrinación es una buena comparación. Otra, holandesa, estudia el efecto del turismo en las fiestas tradicionales. Y quien escribe tiene ya cuatro años confrontándose con

12 Un dato interesante en este sentido es que cuando ya es sumamente dificil ingresar al templo muchos peregrinos colocan sus velas en las partes de la roca de la aparición que ha quedado fuera del templo. Esta roca inicialmente estaba a la intemperie, ahora hace las veces de altar mayor del templo que fue construido sobre ella.

13 No pretendo profundizar en la discusión sobre la forma de relación entre las religiones indigenas y cristianas (sincretismos, resistencias, etc.). Creo que lo que se esboza sobre interculturalidad también es aplicable a estos problemas.

14

Pregunta tomada de Poole (1988) y que en parte inspiró este texto. Esta pregunta se la formuló un peregrino endógeno. Poole la retoma para interpelarse e interpelar a la comunidad académica sobre sus razones para interesarse en la peregrinación de Qoyllur Rit'i. 
sus fantasmas de antropólogo cusqueño de clase media en su relación -no solo de interés académico - con la sociedad cusqueña.

Pero el centro de interés de la mayoría de los peregrinos exógenos pasa por las referencias a los apus, la Pachamama, ${ }^{15}$ los cultos antiguos en relación con la naturaleza. El discurso que no se encuentra fácilmente entre los peregrinos endógenos es reiterativo entre los exógenos. Una estudiante de geografia, peruana - pero que vive hace diez años en Suiza - habla sobre los motivos de su presencia en el santuario: «[...] sobre todo porque yo me considero animista; yo he venido por el apu no por el símbolo de la Iglesia Católica, sino por lo que está detrás; más que nada por eso. Nunca había venido hasta ahora y quería tener un encuentro con el $a p u$. [...]. Siempre que voy a la montaña, hablo con las montañas y siento su energía [...] aquí en la región andina, y lo he experimentado también en otros países, como en el Himalaya. También sentí un contacto con la naturaleza).

Una joven cusqueña, estudiante de Odontología en la Universidad Andina del Cusco, nos dice sobre sus motivos para ir a la fiesta:

E: ¿Por qué viniste?

R: Porque tengo fe, Porque sabía que este lugar era energético y tenía un paisaje precioso.

E: ¿A qué te refieres con energético?

$\mathrm{R}$ : Como soy cusqueña sé que la tradición cuenta mucho, pero también se que los del lugar vienen a hacer como un peregrinaje pero no exactamente al Señor de Qoyllur Rit' $i$, sino a la madre naturaleza.

También estuvo una entrenadora de chamanismo. Hace dieciocho años que vive en Estados Unidos. Alli descubrió todo lo que sabe ahora; aprendió hinduismo, religiones europeas antiguas, chamanismo de los aborígenes norteamericanos. Llegó hasta el santuario con un grupo de discípulos suyos. El conjunto de sus carpas - que incluye una pequeña para baño y otra grande para comedor- está rodeado por un círculo de champas y tiene, de trecho en trecho, una gran pluma de pavo real. También tienen pututos ${ }^{16}$ que tocan en la puerta del templo cuando las comparsas están bailando delante de él.

R: Estoy aquí porque generalmente quiero enseñar a mi gente, a mi nación indígena acerca de la Pachamama y los apus, los padres ancestrales, una religión

15 La madre tierra.

16 Trompetas de caracol marino. Son usadas ritualmente por las comunidades más tradicionales. 
muy ancestral que es la primera religión, antes de las demás religiones. [...] religión de amar a la tierra, de amar al cielo, al Sol, a la Luna. [...] Se originó en todos los sitios del mundo, como se originó aquí en los Andes de Sudamérica. [...] Yo hago entrenamiento de chamanismo en estos momentos $y$ las personas que vienen conmigo son para aprender a pasar a un espiritu superior y asimismo traer sus conocimientos ancestrales de ellos, de sus experiencias, de sus espíritus, para poder enseñar a la gente. Entonces yo estoy haciendo este entrenamiento acá, porque yo considero que este es el lugar más divino y más sagrado, donde nuestros ancestros han dejado muchas de sus sabidurías ancestrales. $Y$ es aquí donde tenemos que escucharlos a ellos.

E: ¿Tú crees que actualmente el campesino peruano viene a relacionarse con la Pachamama y los espíritus de la tierra en forma espiritual, o viene más bien a pedir a una divinidad poder tener un carro, una profesión, una casa, poder salir de la pobreza en la que se encuentra?

R: La pobreza existe dentro de nuestro espiritu y esa es la razón por la cual pedimos, pedimos, pedimos [...] Y cuando la riqueza existe dentro de nuestro espíritu simplemente las cosas llegan espontáneamente a nosotros.

También se respira en los discursos de los exógenos un sentimiento de tristeza o de desencanto al ver que hay comercio, que se juega a obtener bienes materiales. Una estudiante de Trabajo Social, que hace sus prácticas en Perú, habla del asunto. Ella es alemana:

R: No sé... Pienso que es algo comercial, y no sé que es lo que la gente realmente busca. Porque todas estas cosas, las casas, los carros, que si tú los pones tú, los obtienes el próximo año, es realmente materialista, ¿no? Y...

E: $i Y$ tú?

$\mathrm{R}$ : $\mathrm{Y}$ no me gusta.

E: ¿Por qué?

$\mathrm{R}$ : Porque pienso que es una fiesta religiosa y debería ser religiosa, pero es muy materialista.

\section{LOS TURISTAS Y LOS APUS: ALGUNAS TRANSFORMACIONES EN LA TRADICIÓN RELIGIOSA ANDINA}

En lo que sigue intento dar pistas sobre la relación entre el turismo y los procesos de reinvención de la tradición religiosa andina del Cusco contemporáneo Son actores de estas transformaciones desde los campesinos, curanderos y autoridades distritales hasta los turistas interesados por experiencias místicas, pasando por agencias de turismo místico, escritores, músicos, artesanos y an- 
tropólogos. Las tradiciones (re)inventadas adquieren pronto autoridad asociada a un aire muy antiguo, perdido en los orígenes de la historia o de los mitos. Inventar tradiciones es esencialmente un proceso de formalización y ritualización caracterizado por la referencia al pasado e impuesto por repetición. Se usan viejas tradiciones pero se necesitan nuevos lenguajes o se extiende el antiguo vocabulario simbólico más allá de sus límites. Estas tradiciones inventadas llenan solo un pequeño espacio dejado por el declinamiento de costumbres y tradiciones viejas (Hobsbawn 1984: 1-11). Todo este proceso de invención o reconfiguración es una reacción ante los incentivos que se reciben del ambiente social, sea interior o exterior. En este proceso, algunos elementos culturales andinos se conjugan y asocian a lo que la influencia exterior busca: la relación con la naturaleza asociada a lo sobrenatural, a lo prístino.

El universo simbólico alrededor de la naturaleza y del paisaje en los Andes está asociado a lo animado y a su influencia sobre las personas. Se trata de una naturaleza viva en la cual los hombres están insertos. La lógica de los despachos a los apus y a la Pachamama es una lógica de reciprocidad. Se recibe una buena cosecha o salud, y a cambio se da de comer al apu y a la Pachamama, con lo que se establece una relación a largo plazo con estas entidades divinas. Los cusqueños, en general, compartimos una percepción animada del paisaje. Los cerros, las rocas, las lagunas, la lluvia no son simplemente un escenario inanimado donde pasan nuestras vidas. Esta característica se puede reconocer incluso en la producción intelectual. El clásico Nuevo indio de Uriel García es una apología al mestizo andino que se caracterizaría por una personalidad fuerte y una voluntad tenaz. El arquetipo: una imagen romántica del qorilazo $^{17}$ chumbivilcano. Utilizando el determinismo geográfico europeo, en boga en esa época, García intenta explicar estas características por la influencia del agreste, duro y bello espacio andino (García 1973). Esta interpretación tiene mucho que ver con la pervivencia del culto a los apus en sus múltiples versiones: desde el culto cotidiano de los campesinos con las primeras gotas del vaso de licor derramadas en la tierra hasta las sesiones de curanderos urbanos con apus que se presentan y hablan, o los pagos y las iniciaciones en las que participan los turistas.

La riqueza y profusión del patrimonio arqueológico y las múltiples preguntas alrededor de los incas que aún no tienen respuestas satisfactorias son otros espacios en que se encuentran elementos fácilmente asociables con lo sobrenatural. Los mitos que se han venido construyendo sobre los incas, sobre su organización, sobre la justicia que imperaba en el incanato, el bienestar y la gran sabiduría que poseian, crean desde la más tierna infancia una actitud

17 Lazo de oro. Para un análisis sobre la imagen romantizada del qorilazo, vid. Poole 1991. 
abierta a la fascinación y admiración del pasado incaico en los cusqueños contemporáneos.

El interés cada vez mayor de los visitantes extranjeros en la religiosidad y en lo sobrenatural crea, en el Cusco, diferentes tipos de localización y de reacción frente a la propia tradición. En Europa y en los Estados Unidos -principalmente en las generaciones jóvenes- se viene dando un desplazamiento del lugar de lo sagrado que valora más lo vivido y experimentado que lo pensado o reflexionado (Bosch 1993: 29-37). Se busca lo religioso en las tradiciones tribales, en los cultos chamánicos, en la sabiduría prístina de lo premoderno. Este proceso interactúa con el poblador cusqueño principalmente a través del turismo, aunque también mediante todos los medios de comunicación a los que se tiene acceso. Solo un pequeño sector de la sociedad cusqueña mantiene una interacción directa con los turistas. Sin embargo, en esta interacción es donde se originan los imaginarios que están modificando la espiritualidad andina y que rebasan los limites de la interacción directa.

Varias agencias de viajes y turismo cusqueñas ofrecen paquetes esotéricos que incluyen encuentros con sacerdotes andinos, quema de pagos a los apus, meditaciones a la salida del sol en lugares arqueológicos, recorridos por los lugares de iniciación de los sacerdotes andinos (la catedral del Cusco, la laguna de Huacarpay, el templo de la Luna, etc.) e incluso la participación en iniciaciones andinas. También ofrecen tours a la peregrinación de Qoyllur Rit'i. ${ }^{18}$

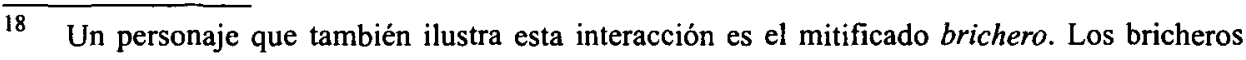
intentan vivir de enamorar extranjeras y hacer que estas los mantengan. Lo curioso es que el discurso de estos amantes vividores está muy relacionado con la espiritualidad andina que ellos supuestamente conocen pues serían sus herederos directos- Dos escritores cusqueños contemporáneos les han dedicado sendos cuentos. Tenemos así «Buscando un Inca» de Luis Nieto Degregori (1992) y «El cazador de gringas» de Mario Guevara Paredes (1994). Aquí un extracto de este último cuento:

"Con la gringuita usé una vieja artimaña que siempre me dio buenos resultados. Se trataba de convencerla de que este encuentro no era casual. Sino que se debía al magnetismo que irradia esta ciudad, haciendo posible que esta noche nos encontráramos, pues hacia tiempo la conocía en sueños. Sonriéndome trató de explicarme sobre los sueños, citando no sé, si a Jung o Adler. Como ve, la gringa intentaba conducirme al campo de la sicología. Entonces, para trastocarle sus teorias, le manifesté que como iniciado en la práctica del conocimiento del mundo mágico andino, tenía otra manera de percibir la realidad. $Y$ no era la realidad simple que ve la mayoría de gente, sino la realidad que está dentro de la misma realidad. $Y$ frente a ello, las intuiciones clínicas o psicoanaliticas nada tenian que hacer, ya que mi percepción provenía y se sustentaba en toda una creencia milenaria que sólo se transmitía a los elegidos» (Guevara 1994). 
Los músicos urbanos cusqueños relacionados con la tradición musical local y, de alguna forma, con el turismo muestran algunas caracteristicas relacionadas con el proceso que ocupa este texto. El grupo Pachatusan ${ }^{19}$ es uno de ellos. En sus presentaciones sus miembros se visten con uncus. ${ }^{20}$ Uno de ellos viste así cotidianamente, además de tener una larga cabellera y sus orejas con los lóbulos perforados, portan orejeras circulares a la usanza de los antiguos nobles orejones. Pachatusan utiliza exclusivamente instrumentos de viento $\mathrm{y}$ percusión, ningún instrumento de herencia colonial. Pututos, quenas, quenachos, tarcas y pincuyllus crean música que busca recuperar los sonidos que escucharon los ancestros incas. Expresión, un grupo más antiguo, en sus presentaciones - que incluyen teatro y danza - viste con atuendos tradicionales de quechuas contemporáneos. En sus primeras producciones Expresión era algo así como una elaborada trova andina basada en la recreación del huayno cusqueño urbano: «Lenta y suavemente / una nube va cubriendo // nuestro Sol histórico / y nuestro pensamiento // Estoy buscando un hermano / que solo ofrezca su canto // que quiera seguir regando / semillas de su pasado // Levántate ahora hermano / y observa a tu pueblo al fin // enciende fuego en tu manto / mi raza no acaba aquí». ${ }^{21}$

$\mathrm{Su}$ última producción es un disco compacto editado en Europa, titulado $Q$ 'eros y dedicado al famoso "último ayllu inca». En este disco, Expresión se vuelca hacia la experimentación. La larga introducción a «Hanan Pacha», un himno religioso escrito para flautas y con coros en quechua, en el siglo XVI, es el intento de creación de un ambiente místico y ancestral, alejado en el tiempo y rondando lo sobrenatural. De varias de las otras canciones se puede decir lo mismo («Mukuku Hina», «Ninapaq», «Raq'chi, Haylli»). Con diferencias, ambas agrupaciones muestran tendencias hacia la exploración de sonidos místicos, ancestrales, telúricos. De esta forma se hacen parientes de la música de la Nueva Era.

Muchos grupos esotéricos se encuentran dedicados a la tarea de desentrañar la sabiduria ancestral andina hace ya algunas décadas. Las publicaciones sobre el esoterismo andino son ya muy numerosas. Antón Ponce de León es autor de dos de ellas. Y el anciano habló..., su primera novela (1987), narra la iniciación del protagonista en el sacerdocio andino al acceder a una aldea invi-

19 Punto de apoyo del universo. Nombre de una montaña cercana al Cusco, en cuyas faldas se encuentra el santuario del Señor de Huanta.

20 Prenda de vestir incaica.

21 «Winchasun» ('Venceremos'). Huayno marinera. Incluido en la producción Nawpa Taki del grupo musical Expresión. 
sible y a unas grutas en las que se hallan las momias de los incas. Su novela termina cuando se le encarga al protagonista fundar el Samana Wasi, ${ }^{22}$ un centro de crecimiento espiritual que inicialmente funcionaría como orfanatorio y asilo (Ponce de León 1987). El Samana Wasi existe en Yucay y es objeto de donaciones que se pueden hacer con el formato que está incluido en la última página del libro. «La admirable organización comunitaria inca basada en tres preceptos legislativos: Trabajo, veracidad y honradez, que tuvo en el Ayllu su célula socio-económica sustentada en dos instituciones de trabajo: El ayni y la minca; así como las sabias enseñanzas de un anciano quechua, jefe políticoreligioso, que conocí en el pasado, sirvieron de inspiración para fundar en un terreno de mi propiedad sito en Urubamba la Fundación Samana Wasi» (Ponce de León 1991: 6).

El Samana Wasi es actualmente un orfanato y un espacio en el cual esta organización realiza sus ceremonias. Los niños que viven en él son enviados por autoridades judiciales de menores del Cusco y, hasta donde se puede apreciar, gozan de una vida carente de necesidades y reciben una educación esmerada. Posteriormente publicó otra novela, En busca del Anciano. Introduzco un párrafo de la reseña que hace de este libro Rubén Pilares en Sieteculebras, revista cultural cusqueña:

Para el lector suena a ingenuidad o chanza leer que un pretendido «Maestro Illac Uma... heredero de la tradición kechua y cosmología» (pág. 15) pontifique sobre los Vedas, las propiedades curativas de los orines y la Biblia, Religiones Ocultas, átomo simiente, facultades y poderes superiores, etcétera; que afirme impertérrito que «Jesús fue el Inti más grande que llegó a la tierra hasta ahora» (pág. 26) y "que ha sido considerado por nosotros como un Illac Uma del Tercer Peldaño» [...] y en parte alguna de la novela exponga o siquiera transparente algo de las concepciones metafísicas andinas y su peculiar idiosincrasia. (Pilares 1995)

Otros acercamientos a la tradición iniciática andina la consideran única y con una forma propia de acercarse a lo sobrenatural. No se puede pretender entenderla sin antes haberse despojado de una «mentalidad modernista y occidentalizada, pues todo ello no es más que una expresión materialista que pretende que mediante la aplicación de un recetario, léase técnicas fenomenológicas, se pueda conseguir una iniciación en una forma tradicional» (Navarro 1991: 5).

22 La casa del descanso. 
Desde la Antropología, Juan Víctor Núñez del Prado habla del sacerdocio andino actual: de todos los rituales que se tiene que pasar para subir en las escalas jerárquicas, de los ritos de pasaje, de las pruebas, de los lugares sagrados donde se llevan a cabo estas ceremonias. Da una imagen de una jerarquía sólida y muy estructurada. Esta jerarquía no se puede percibir normalmente pues está oculta, guardando los secretos de la sabiduría incaica (Núñez del Prado y Murillo 1991: 26-34). Núñez del Prado también trabaja como guía de turismo místico y conduce grupos hasta la comunidad de Q'ero.

En este contexto no es sorprendente - de acuerdo con la política de revalorización de lo cusqueño liderada desde la Municipalidad del Qosqo- que en la ceremonia de inauguración de la Plaza del Tricentenario - en homenaje a la Universidad Nacional San Antonio Abad del Cusco- se haya realizado un pago a la tierra quemando el despacho. El encargado fue un curandero andino ayudado por dos jóvenes campesinas, todos vestidos con trajes tradicionales.

Pero estos procesos no solo involucran a agencias de turismo, místicos, intelectuales, músicos y autoridades urbanas. En este proceso también participan activamente autoridades de distritos rurales, curanderos y campesinos. La tradición espiritual andina se torna en una fuente prestigio y en una nueva estrategia económica respaldada por los discursos sobre la revalorización de lo indígena - muy antiguos en el Cusco-, la importancia y difusión actual de diferentes discursos ecológicos y la búsqueda de experiencias religiosas prístinas y exóticas por parte de un buen sector de turistas que llegan a estas tierras.

Huasao, a escasos $30 \mathrm{~km}$ de la ciudad del Cusco, camino a Urcos, ha sido tradicionalmente un pueblo de curanderos. Desde 1995, cada agosto se realiza el «Kintu Raymi: Encuentro de curanderos andinos». Viene siendo organizado por iniciativas privadas, unas veces, y por la municipalidad de Huasao y la comunidad campesina, otras, no sin conflictos, acusaciones de malversación y exigencia de beneficios para el pueblo. Se invita a numerosos curanderos de toda la zona del Cusco. En un salón grande se arman pequeñas celdas en las que cada curandero atiende. El público que viene, principalmente de la ciudad del Cusco, encuentra una pizarra con una lista de los curanderos y el número de celda correspondiente. Por cinco soles se obtiene el derecho de ingresar a una consulta. En esta consulta, normalmente el curandero ve coca, lee cartas o aplica algún otro método para poder decir al paciente qué problemas tiene $\mathrm{y}$ cuáles podrían ser las soluciones. Una vez terminado el diagnóstico, si el cliente lo desea puede tomar los servicios del curandero para algún ritual más elaborado como romper un daño, cambiar la suerte o recuperar al amor perdido. Los arreglos y pagos para estos trabajos más complejos ya son tratos entre el curandero y el cliente, sin intervención de los organizadores. 
Por espacio de dos semanas, los curanderos atienden al variado público que asiste. Principalmente, los que acuden son cusqueños urbanos. Se puede encontrar alguno que otro extranjero atraído por los afiches publicitarios del evento que se encuentran en el centro de la ciudad. Son curanderos de la ciudad del Cusco, los de Ollantaytambo, de Paucartambo, y también los famosos Q'eros. Especial atención gozan los curanderos puneños y bolivianos. Hay algunos de otros departamentos como Ayacucho, Apurímac y Huancavelica. El primer año del festival estuvo marcado por el éxito rotundo que tuvieron dos curanderos Q'eros que, paradójicamente, llegaron por accidente al evento. Uno de los curanderos que acudió en 1998 era de Ollantaytambo. Se trata de un comunero que ahora se dedica cada vez más a trabajar como porteador en el Camino Inca a Machu Picchu. ${ }^{23}$ Con el tiempo ha llegado a ser jefe de una cuadrilla de porteadores. Él recibe una paga por esta labor, pero además, recibe un pago adicional porque lee la coca a los turistas como parte del tour. Ya trabaja cerca de diez años con esta agencia de viajes.

La experiencia de Huasao en la creación de este tipo de eventos no es la única. Ccatcca es un pequeño pueblo que se encuentra a $20 \mathrm{~km}$ de Ocongate. Desde 1995 ostenta el título de "Capital de la espiritualidad andina». Este título lo sostiene por su cercanía al santuario de Qoyllur Rit'i y al nevado Ausangate. Las autoridades de Ccatcca ya han organizado una fiesta alrededor de la espiritualidad andina: Pachamama Raymi. Del 25 de julio al 1 de agosto, cuando la Pachamama «se abre». El 31 de julio es un día especial para los campesinos de la zona; ese día la Pachamama puede ser muy generosa. Y si uno encuentra una illa (una piedra pequeña de forma de ganado o con una forma extraña) tendrá mucho éxito en la crianza de sus animales. En 1997, el afiche que promocionaba esta fiesta incluía entre sus actividades: «Santo Juñunacuy», "Corrida de toros con el apu cóndor» y un «Pago a la tierra». La festividad estaba organizada por la Municipalidad Distrital de Ccatcca y trataba de llamar la atención de los turistas mediante afiches colocados en el centro de la ciudad del Cusco.

Otro caso ilustrativo es el de la comunidad campesina de Machu Pitumarca; Pitumarca es un anexo de la provincia de Canchis, recientemente ha sido elevado a la condición de distrito. Machu Pitumarca acude a la peregrinación del Señor de Qoyllur Rit'i con un conjunto de ukukus. A veces llevan alguna comparsa, pero lo normal es que solo vayan ukukus acompañados por un

$23 \quad$ Los porteadores son personas que cargan el equipaje, los alimentos y carpas, entre otros pertrechos, de grupos de turistas que hacen el Camino Inca. Muchos son comuneros de la zona de Ollantaytambo. 
conjunto musical de pitos y tambores. Sin embargo, al concurso regional de danzas folklóricas de Raqchi no llevan a los ukukus. La comunidad de Machu Pitumarca fue la ganadora de este concurso en 1997 y 1998. Ellos dicen que decidieron reponer una danza antigua, de sus tatarabuelos. Se visten con sus tradicionales pantalones cortos y negros, pero también con uncus negros y chullos del mismo color. Para completar el atuendo usan porras de piedra que dicen haber encontrado al trabajar sus tierras. Se trata de una danza nueva, sin antecedentes en el repertorio de las danzas rituales de la región. Se llama Machu tusuy ('danza de los antiguos, de los viejos') y según dicen, se ejecutaba en honor a los apus y es bailada por sus guardianes. En general, los danzantes son personas bastante jóvenes y bilingües. No es casual que sean los mismos que tienen mayor acceso a los espacios urbanos los mas permeables a su influencia.

\section{ENTRE EL BUEN (Y SABIO) SALVAJE Y LOS APUS ANDINOS}

Es innegable que los procesos a los que se ha hecho referencia no involucran a toda la población rural cusqueña y ni siquiera a la urbana. Se trata de pequeños segmentos de población rural que tienen interacción directa o indirecta con los discursos que se elaboran influenciados por el turismo. No pretendo sostener que estos procesos son extendidos a toda la población rural o que no se están dando otros procesos paralelos y relacionados que tienen que ver con la espiritualidad y la religión. Es evidente la presencia de los grupos evangélicos entre los comuneros cusqueños, con sus efectos sobre el consumo de alcohol, las fiestas patronales y los trabajos comunales, o la incursión de los Israelitas del Nuevo Pacto Universal con sus mostachos, largas cabelleras y sus discursos apocalípticos.

Lo que se busca es mostrar los indicios de un proceso de reelaboración de los discursos, las prácticas, los rituales, la parafernalia relacionada con la espiritualidad andina tradicional. Se está hablando en particular de aquello relacionado con el culto a las deidades locales relacionadas con la naturaleza: los apus, el Roal, y a la deidad más general y englobante, la Pachamama.

Respecto a los motivos de los peregrinos endógenos y exógenos, y la supuesta dicotomía entre intereses materiales e intereses espirituales, considero que esta oposición es clara y evidente para los exógenos - los turistas, los investigadores y los que comparten una cultura urbana-, quienes asocian lo material con la satisfacción de las necesidades más básicas, con lo terrenal, con lo monetario (como el "sucio dinero») y con todo un universo de referencias que asimilan al egoísmo, la avaricia, la corrupción, así como a los 
placeres, lo sensual, lo corporal, lo inmediato, lo fugaz. Lo espiritual, en cambio, lo relacionan con lo elevado, con las necesidades sublimes, con lo trascendente, con lo absoluto y - más allá - con el amor, el desprendimiento, la felicidad.

Sostengo que esta dicotomía no se encuentra presente de la misma manera - ni con las mismas relaciones con otros conceptos - en la cultura campesina andina de la zona, ni en la población campesina que migra al Cusco. La producción agrícola y la ganadera satisfacen -en la medida de lo posiblebuena parte de las necesidades de esta población. Ambas producciones se encuentran relacionadas directamente con la tierra, los pastos y la lluvia, entre otros elementos de la naturaleza, que, a su vez, se relacionan estrechamente con las divinidades. El mundo ritual, religioso, espiritual no se encuentra separado del mundo de la producción y satisfacción de necesidades como alimentación, vestido, educación, etc. Como dije antes, creo que el imaginario religioso cristiano y el de las divinidades locales relacionadas con la naturaleza conforman un sistema con cierto grado de coherencia. En este sentido, el acercamiento hacia la divinidad cristiana está cargado de elementos dados por su relación con los dioses locales. Asimismo, la actitud de acercarse al Señor con peticiones materiales es parte de lo mismo.

Los peregrinos exógenos son personas que cargan con la dicotomía entre lo material y lo espiritual. También es un elemento importante para entenderlos el hecho de que sean en su mayoría personas cuya situación material es mucho menos riesgosa y más acomodada que la de los campesinos andinos. Sus inquietudes al acudir a Qoyllur Rit'i se inclinan más al lado espiritual. Allí se encuentran con la gran mayoría de endógenos que no están actuando en función de la dicotomía en cuestión. La decepción de los exógenos, al no encontrar una religiosidad espiritual prístina no contaminada por lo material, es la evidencia de un desencuentro entre las categorías sobre las cuales se construye el entendimiento de la relación con las divinidades y sus espacios de acción dentro de la vida cotidiana.

Una gran parte de los peregrinos que le dan personalidad inconfundible a esta peregrinación son jóvenes campesinos y urbanos que se caracterizan por tener una movilidad espacial muy grande. Son el segmento campesino que mayor interacción ha tenido con los espacios más modernos de nuestra sociedad. La gran mayoría ha trabajado o trabaja en el Cusco o Lima en alguna temporada de su vida. Sea a través de una migración temporal anual que se coordina con sus labores agropecuarias, sea como migrante definitivo en la 
ciudad desde la cual visita cada ciertos meses a su familia campesina, los jóvenes han tenido una experiencia urbana importante.

Ellos han tomado las riendas en las organizaciones campesinas, son los que mayor experiencia tienen del mundo exterior, los que manejan sus herramientas como saber leer y escribir. Son la avanzada moderna de una cultura campesina cada vez más urbana. Estos jóvenes son al mismo tiempo los que le dan vida a esta peregrinación que reúne múltiples elementos que se podría calificar de sumamente tradicionales y que en estos tiempos de modernización se encuentran en crecimiento.

Así, el ser urbano y trabajar dentro de una economía más monetaria que de autoconsumo no impide acudir con todo fervor al Señor de Qoyllur Rit'i que, a su vez, muestra elementos tanto cristianos como de religión indígena. Los peregrinos endógenos no encuentran ninguna contradicción en este hecho. Con zapatillas y una mochila al hombro se detendrán antes de la primera cruz del santuario. Después de extraer de su mochila sus vestidos de $u k u k u s$ o danzantes, se cargarán de ellos, de sus látigos y máscaras, de sus personajes, y así entrarán como comparsa dirigiéndose a presentar su saludo al Señor. En medio de este ceremonial aceptan sin mayor problema las cámaras y establecerán interacciones con estas para, en algunos casos, pedir alguna retribución económica. Su facilidad para trocarse en otros, para circular entre espacios culturales relativamente diferentes sin dificultades y sin encontrar contradicciones, es lo que permite la construcción de nuevos escenarios culturales y, en las ciudades, nuevas culturas urbanas.

Por otro lado, los turistas en busca de lo místico - que tampoco son todos - se acercan hacia lo andino con una versión actualizada del mito del buen salvaje, que convierte al andino no solo en bueno sino, también, en sabio. Según este mito, las culturas tradicionales han logrado mantener a través de los tiempos una relación armoniosa con la naturaleza. Esta relación armoniosa tiene un correlato con un universo místico y divino animista. Las montañas, los ríos, los lagos no son cosas inertes; son seres vivos, espirituales, con los cuales los individuos de estas culturas logran comunicarse. La inquietud por una relación mística se encuentra afianzada por el discurso ecológico que logra cada vez mayor público y mayor importancia desde hace ya décadas. Este -como la fragmentación religiosa-, es un proceso global. La otredad, lo exótico, tiene una misteriosa capacidad de fascinación. Ocurre no solo con jóvenes europeos que viven en el vértigo y la soledad de las grandes ciudades, o con los campesinos de la sierra del Perú. Toda cultura muestra una mezcla de miedo y fascinación por los otros, los que están más allá del grupo, a los que usualmente no se los clasifica dentro de la categoría de humanos como no- 
sotros. ${ }^{24}$ Lo otro es peligroso, pero también es poseedor y fuente de poderes misteriosos. En los otros culturales, en las elaboraciones que se hacen sobre ellos, se proyectan muchas de las necesidades y anhelos que se tiene alrededor de lo que se querría cambiar en la propia sociedad o sobre las propias imágenes de una sociedad ideal. ${ }^{25}$

La sabiduría ancestral en la relación con la naturaleza, buscada por los turistas, es más una necesidad y un anhelo que una realidad andina concreta. ${ }^{26}$ En la peregrinación de Qoyllur Rit ' $i$, la conducta de los visitantes endógenos está fundamentalmente motivada por el encuentro que tendrán con un espacio y un tiempo sagrados que pueden ser capitales en la mayor o menor facilidad de conseguir algún objetivo en sus actividades cotidianas; están lejos de buscar interacciones u obtener beneficios de los exógenos. No sucede lo mismo en los otros espacios de interacción que se mostró. En los encuentros de curanderos, en las fiestas en torno a la espiritualidad, en la tarea de las lecturas de coca en el Camino Inca hay una participación voluntaria en engarzar la propia tradición con los requerimientos de productos culturales que traen los turistas y las nuevas valoraciones que esto produce, sea directa o indirectamente.

Las iniciativas de alcaldes y autoridades, creando eventos relacionados con esta demanda cultural, son una reacción ante un espacio de prestigio novedoso que se vincula con las propias tradiciones culturales. Al mismo tiempo, son esfuerzos por atraer el turismo y promover el desarrollo económico en sus localidades. El hecho de declararse "Capital de la espiritualidad andina" o de favorecer la fama de ser un centro de curanderismo andino no están en contradicción con los afanes de las autoridades por el «progreso» de sus distritos y porque sean «turísticos y ecológicos». La reinvención de danzas y los cambios en el lenguaje de curanderos muestran lo mismo a un nivel más rural.

La cultura, en general, es un permanente e inacabado proceso de reelaboración y de cambio que persistirá mientras esté viva. De las características particulares del proceso, de la influencia externa y de los medios de comunicación, y de las formas en que los campesinos andinos vayan procesando estas influencias - y reaccionando-, dependen las modificaciones y la futura configuración del culto a los apus y a la Pachamama. La tradición espiritual andina puede convertirse $-\mathrm{y}$ este fenómeno ya ocurrió para unos pocos campesinos

24 Vid. Brightman 1990; Bartra 1994; Sayre 1997.

25 También en los otros se puede proyectar lo negativo, lo no-humano, lo irracional. Evidentemente, este hecbo depende de los contextos políticos.

26 En este texto no se pretende hacer juicios sobre la trascendencia espiritual de la tradición religiosa andina. Aqui solamente se trata de mostrar procesos que se vienen dando en ciertos espacios relacionados con esta tradición. 
quechuas- - en una fuente de prestigio y en una novedosa estrategia económica o un capital cultural monetarizable.

Veo ambiguo el efecto de este proceso en el estatus de la tradición cultural quechua. Pues si bien, por un lado, tiende a revalorizarla y ponerla en el estatus de otras grandes tradiciones espirituales; por el otro, apela a sus características más exotizantes. En todo caso, la rapidez y naturalidad con que las poblaciones campesinas procesan estas influencias es una de sus mayores herramientas para utilizar estos procesos en su beneficio al mismo tiempo que transforman y reproducen su cultura.

\section{REFERENCIAS}

ANSIÓN, Juan

1994 «Cambios culturales en al sociedad rural: El paradigma indigenista en cuestión». En Perü: El problema agrario en debate. Eds., Óscar Dancourt, Enrique Mayer y Carlos Monge. Lima: SEPIA-Universidad Nacional San Agustín.

BARTRA, Roger

1994 Wild Men in the Looking Glass. The Mythic Origins of European Otherness. Ann Arbor (Michigan): University of Michigan Press.

BOSCH, Juan

1993 Para conocer las sectas. Panorámica de la nueva religiosidad marginal. Navarra: Verbo Divino.

BRIGHTMAN, Robert A.

1990 «Primitivism in Missisippi Cree historical consciousness». Man 25. 1: 108128.

DÁVILA, Adriana

1996 «Pucllanapampa: donde uno va a soñar para que después se haga realidad». Informe mimeografiado. s.d.

FLORES, Carlos

1997 El Taytacha Qoyllur Rit'i. Teologia india hecha por comuneros y mestizos quechuas. Sicuani: Instituto de Pastoral Andina.

FLORES OCHOA, Jorge y Ana María FrIes

1989 Puna, qheswa, yunga: el hombre y su medio en Q'ero. Lima: Banco Central de Reserva del Perú. 
FUENZALIDA, Fernando

1993 «La cuestión del mestizaje cultural y la educación en el Perú de nuestros días». En Anthropologica 10. 10: 7-25.

GARCÍA, Uriel

1973 El Nuevo Indio. Lima: Editorial Universitaria.

GEERTZ, Clifford

1973 The Interpretation of Cultures: Selected Essays. Nueva York: Basic Books.

GOLTE, Jürgen

1981 «Qué es la cultura frente a la historia?». La Revista. 4.

GONZALES DE OLARTE, Efrain

1994 En las fronteras del mercado. Economia politica del campesinado en el Perú. Lima: Instituto de Estudios Peruanos.

GOW, Rosalind y Bernabé CONDORI

1982 Kay Pacha. Cusco: Centro Bartolomé de las Casas.

GUEVARA, Mario

1994 Cazador de gringas y otros cuentos. Cusco: Municipalidad del Qosqo.

HALL, Stuart

1995 «Negociating caribean identities». New Left Review. 205: 3-14.

HOBSBAWN, Eric

1984 «Inventing Traditions». En The invention of tradition. Eds., Hobsbawn y Ranger. Londres: Cambridge University Press. Introducción.

LAUER, Mirko y Henrique URBANO, eds.

1991 Poder y Violencia en los Andes. Cusco: Centro Bartolomé de las Casas.

NAVARRO, Alcídes

1991 Editorial. Gnosis. Revista de esoterismo iniciático 5. Cusco.

NIETO, Luis

1992 Señores destos reynos. Lima: PEISA.

NÚÑEZ DEL PRADO, Juan Víctor y Lida MURILLO

1991 «El sacerdocio andino actual». Gnosis. Revista de Esoterismo Iniciático 5. Cusco. 
ORTIZ RESCANIERE, Alejandro

1998 El individuo andino contemporáneo. Sobre el andino, los prejuicios y el racismo. Lima: CISEPA-PUCP. ${ }^{27}$

PILARES, Rubén

1994 Reseña: En busca del Anciano. Sieteculebras. Revista de Cultura Andina. Nueva Epoca. 8.

PONCE DE LEÓN, Antón

1987 Y el anciano habló... Cusco: s.d.

1991 «Fundación Samana Wasi». Gnosis. Revista de Esoterismo Iniciático. 4.

1993 En busca del Anciano. Cusco: Municipalidad del Qosqo.

POOLE, Deborah

1988 «Entre el milagro y la mercancía: Qoyllur Rit'i». Márgenes. 4. Año 2.

1991 «El folklore de la violencia en una provincia alta del Cuzco». En Poder y Violencia en los Andes. Eds., Mirko Lauer y Henrique Urbano. Cusco: Centro Bartolomé de las Casas.

REMY, María Isabel

1991 «Los discursos sobre la violencia en los Andes. Algunas reflexiones a propósito del Chiaraje». En Lauer y Urbano 1991.

SAYRE, Gordon M.

1997 Les Savages Américains. Representations of Native Americans in French and English Colonial Literature. Chapel Hill: University of North Carolina Press.

SAHLINS, Marshall

1988 Islas de historia. La muerte del capitán Cook. Metáfora, antropología e historia. Madrid: Gedisa.

27 Existe una versión corregida publicada posteriormente, bajo el nombre de «Capítulo 9: En torno al individuo andino. Identificaciones prejuicios y seudorracismo». En: Ortiz Rescaniere, Alejandro: La pareja y el mito. Estudios sobre la persona y la pareja en los Andes. $3^{\text {a }}$ ed. Lima: Fondo Editorial PUCP, 2001. 
